\title{
An Unusual Cause of Gastrointestinal Bleeding: Duodenal Lipoma
}

\author{
R. Kadaba ${ }^{a}$ K.A. Bowers ${ }^{a} \quad$ N. Wijesuriyab $\quad$ S.L. Preston ${ }^{c}$ \\ G.B. Bray ${ }^{\text {d H.M. Kocher }}{ }^{\mathrm{a}}$ \\ ${ }^{a}$ Barts and The London HPB Centre, Departments of ${ }^{b}$ Histopathology and \\ 'Gastroenterology, The Royal London Hospital, and ${ }^{\mathrm{d}}$ Department of \\ Gastroenterology, Southend University Hospital, London, UK
}

\section{Key Words}

Endoscopy $\cdot$ CT scan · Surgery · Submucosal excision

\begin{abstract}
Common causes of chronic upper gastrointestinal bleeding include oesophageal varices, gastroduodenal ulcers and malignancy, and patients mostly present with iron deficiency type anaemia. We present the case of a 60-year-old lady who presented with iron deficiency anaemia and on investigation was found to have a large duodenal polyp requiring surgical excision. On histological examination, the polyp was revealed to be a lipoma. We review the recent literature and formulate a management plan for this rare entity.
\end{abstract}

\section{Case Report}

A 60-year-old lady presented to her general practitioner with symptoms of fatigue, tiredness and generally being unwell. Upon investigation, she was found to have iron deficiency anaemia (haemoglobin $6.5 \mathrm{~g} / \mathrm{dl}$ ). She did not report any haematemesis or melaena, weight loss, abdominal pain or vomiting and had no significant family history or risk factors for gastrointestinal pathologies. Following blood transfusion, she underwent endoscopy and was found to have a large polyp in the first part of the duodenum (D1). The polyp had a broad base of more than $1 \mathrm{~cm}$ in the proximal D1 and extended just proximal to the ampulla, involving the superior 180 degrees of the duodenal wall (fig. 1). Multiple biopsies demonstrated duodenal mucosa with moderate chronic inflammation and foci of gastric epithelium. CT scan confirmed a solitary $6 \times 3 \mathrm{~cm}$ duodenal polyp with duodenal intussusception (fig. 2). A repeat upper gastrointestinal endoscopy, again with multiple biopsies (small intestinal type mucosa with villi lined by mildly dysplastic epithelium) of this solitary polyp did not shed any further light on the subject.

The lesion was further assessed by endoscopic ultrasound (EUS) which excluded any invasive component and suggested possible duodenal lipoma based on ultrasound characteristics. Endoscopic mucosal resection was not considered feasible due to the size of the lesion, as well as the large base with which it was attached to the first part of the duodenum. Hence a transduodenal resection of the polyp in

Hemant M. Kocher, MS, MD, FRCS Centre for Tumour Biology, Barts Cancer Institute, Queen Mary University of London Charterhouse Square, London EC1M 6BQ (UK)

Tel. +44 207882 3579, E-Mail hemant.kocher@bartsandthelondon.nhs.uk 
the submucosal plane was performed, with a sleeve of surrounding mucosa to excise all grossly abnormal mucosa. The patient made an uncomplicated recovery from surgery and was discharged home on the sixth postoperative day. The macroscopic appearance of the lesion is shown in figure 3 . Final histopathological examination revealed the lesion to be a submucosal lipoma with overlying mucosal prolapse and reactive/regenerative atypia.

An online search in PubMed for 'duodenal lipomas' generated 174 articles, of which 26 were specific for duodenal lipomas and in English. Of these 26 articles, 9 case reports were identified to have been published in the last 10 years. The main features of these case reports are summarised in table 1 . The age of the patients ranged from 46 to 81 years with 5 females and 4 males and most of them presented with melaena. Three patients had abdominal pain and discomfort. The size of the tumours ranged from 2 to $5 \mathrm{~cm}$ and most of them were excised endoscopically. Huang et al. [1] report two cases wherein, despite the tumours being small (less than $3 \mathrm{~cm}$ ), both patients were symptomatic with postprandial abdominal fullness and were treated with endoscopic excision. In our patient, the size of the lesion was $6 \times 3 \mathrm{~cm}$, which is the largest in comparison to the published reports. Endoscopic excision was unsuccessful due to the size of the lesion. Postoperative recovery was uneventful and on subsequent follow-up, her anaemia ameliorated and she did not suffer from any long-term complications.

\section{Discussion}

Duodenal lipoma is a relatively uncommon benign tumour of the gastrointestinal tract. A study by Mayo et al. [2] showed that out of 4,000 cases of benign gastrointestinal tumours, 164 (4\%) were lipomas. The site most common was the colon $(64 \%)$, followed by small intestine (26\%), duodenum (4\%), stomach (3\%) and oesophagus (2\%). In the duodenum, lipomas tend to be noted mostly in the second part and are most often situated in the submucosal plane, but can also be subserosal and can be sessile or pedunculated.

Duodenal lipomas are incidental diagnoses on endoscopy or surgery as they are asymptomatic. The occurrence of symptoms, if any, largely depends on the size of the lesion. Tumours greater than $4 \mathrm{~cm}$ can produce symptoms of abdominal pain and discomfort or cause hypochromic microcytic anaemia due to ulceration and bleeding, or intestinal obstruction due to intussusception [3]. Acute haemorrhage is a rare complication with fewer than 15 cases reported $[4,5]$.

Direct visualisation at endoscopy will provide a clue to the nature of the tumour, however, as duodenal lipomas are submucosal, superficial biopsies will not be sufficient and deeper biopsies will be needed to provide a definitive diagnosis. Imaging modalities such as CT scan and EUS have greatly improved the ability to characterise benign upper gastrointestinal tumours. CT scan of the upper gastrointestinal tract can fairly accurately facilitate the preoperative diagnosis of lipoma based on low attenuation signals of -50 to -100 Hounsfield units [6]. EUS features of a homogenous, hyperechoic mass within the submucosal layer are highly characteristic of duodenal lipomas and in addition, EUS can also visualise the depth and invasion [7].

Symptomatic duodenal lipomas warrant treatment. The recommended treatment is endoscopic excision if the lesion is polypoid and of manageable size. For large and sessile lesions, endoscopic excision may prove technically difficult and increase the risk of bleeding and perforation [8], thus surgical excision would be the preferred approach in such cases. 
In conclusion, duodenal lipomas are uncommon benign tumours that can present with signs and symptoms of upper gastrointestinal bleeding. They can be suspected on endoscopic visualisation but may require CT or EUS for further evaluation. Endoscopic excision is the preferred treatment, but if the size of the lesion precludes endoscopy, surgical excision is the treatment of choice.

\section{Disclosure Statement}

The authors have no conflicts of interest to declare.

Table 1. Summary of case reports of duodenal lipoma in the last 10 years

\begin{tabular}{|c|c|c|c|c|}
\hline Reference & Age, sex & Presentation & Tumour size & Treatment \\
\hline Chang et al. [9] & $59, \mathrm{~F}$ & melaena & $4 \mathrm{~cm}$ & surgical excision \\
\hline Mohamed et al. [10] & $70, \mathrm{~F}$ & anaemia, melaena & $5.5 \times 1 \mathrm{~cm}$ & endoscopic excision \\
\hline Huang et al. [1] & $46, \mathrm{M}$ & postprandial fullness & $2 \mathrm{~cm}$ & endoscopic excision \\
\hline Huang et al. [1] & $75, \mathrm{~F}$ & postprandial fullness & $2 \times 1.5 \mathrm{~cm}$ & endoscopic excision \\
\hline Murata et al. [11] & $67, \mathrm{M}$ & anaemia, melaena & $4 \times 1.2 \mathrm{~cm}$ & endoscopic excision \\
\hline Long et al. [12] & N/A & bleeding & $4 \mathrm{~cm}$ & endoscopic excision \\
\hline Sou et al. [13] & $81, \mathrm{~F}$ & anaemia, melaena & $5 \mathrm{~cm}$ & endoscopic excision \\
\hline Blanchet et al. [3] & $69, \mathrm{~F}$ & nausea, vomiting, abdominal pain & $5 \times 3 \mathrm{~cm}$ & endoscopic excision \\
\hline Tung et al. [4] & $73, \mathrm{M}$ & anaemia, melaena & $4.5 \times 1.6 \mathrm{~cm}$ & endoscopic excision \\
\hline
\end{tabular}




\begin{tabular}{|c|c|c|}
\hline Case Reports in & \begin{tabular}{|l} 
Case Rep Gastroenterol 2011;5:183-188 \\
DOl: 10.1159/000327219
\end{tabular} & $\begin{array}{l}\text { Published online: } \\
\text { April 13, } 2011\end{array}$ \\
\hline
\end{tabular}

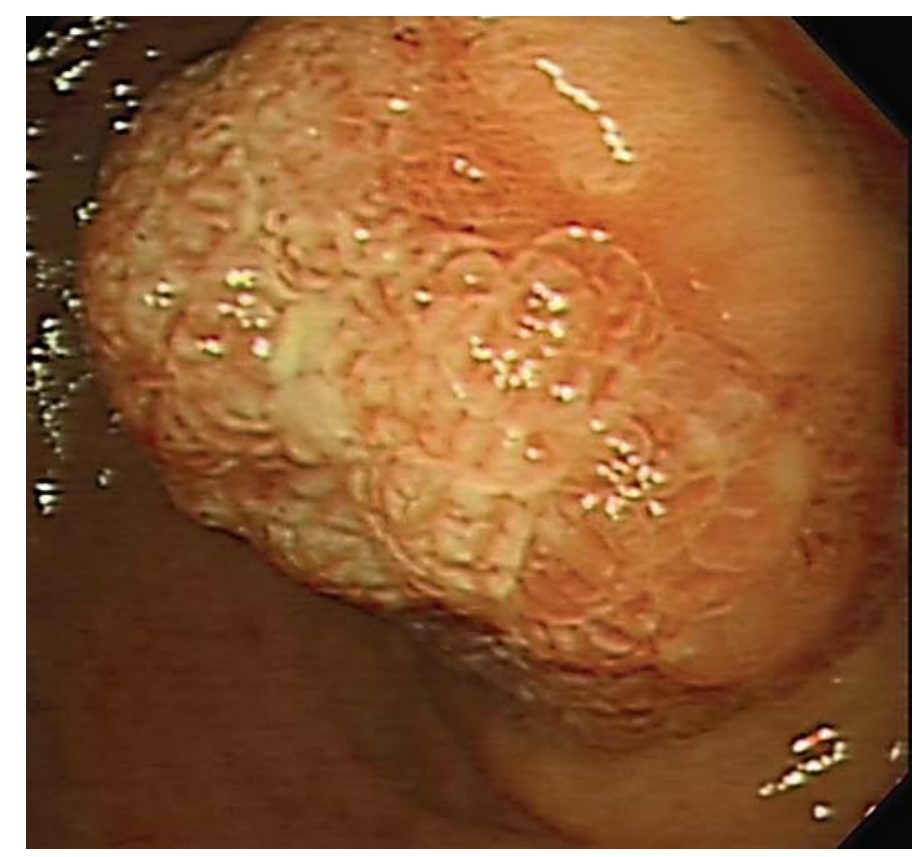

Fig. 1. Endoscopic appearance of the polyp arising from D1, demonstrating the ulcerated surface and a broad base.

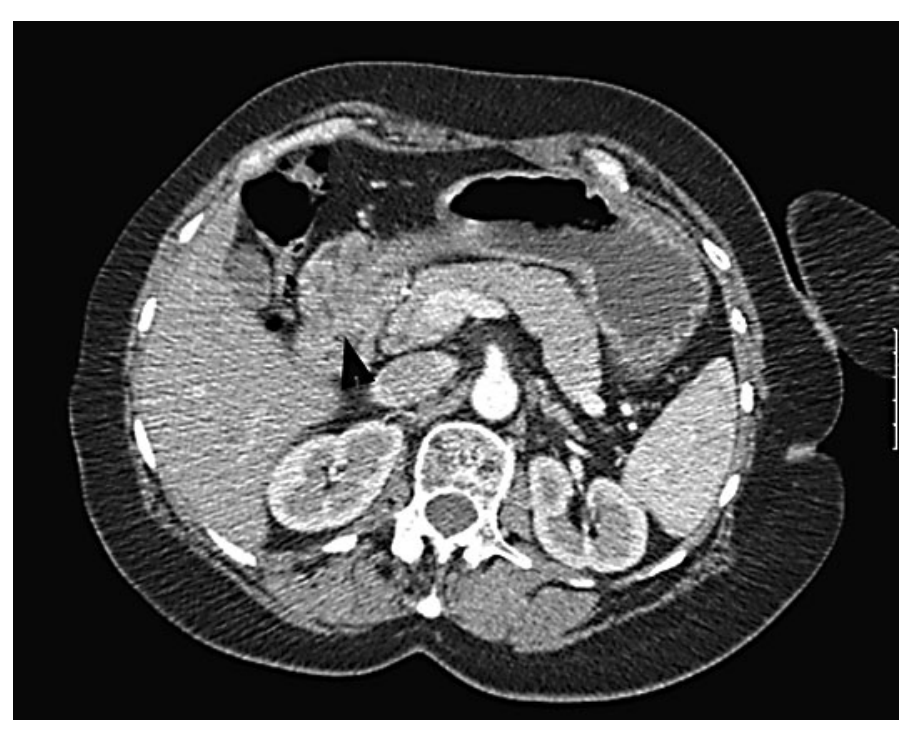

Fig. 2. CT showing large D1 polyp intussuscepting into D2 (arrowhead), but no obvious CT scan characteristics of a lipoma. 


\begin{tabular}{r|l|l|l} 
Case Reports in & $\begin{array}{l}\text { Case Rep Gastroenterol 2011;5:183-188 } \\
\text { DOI: 10.1159/000327219 }\end{array}$ & $\begin{array}{l}\text { Published online: } \\
\text { April 13, 2011 }\end{array}$ & $\begin{array}{l}\text { (2011 S. Karger AG, Basel } \\
\text { ISSN 1662-0631 } \\
\text { www.karger.com/crg }\end{array}$ \\
\hline
\end{tabular}

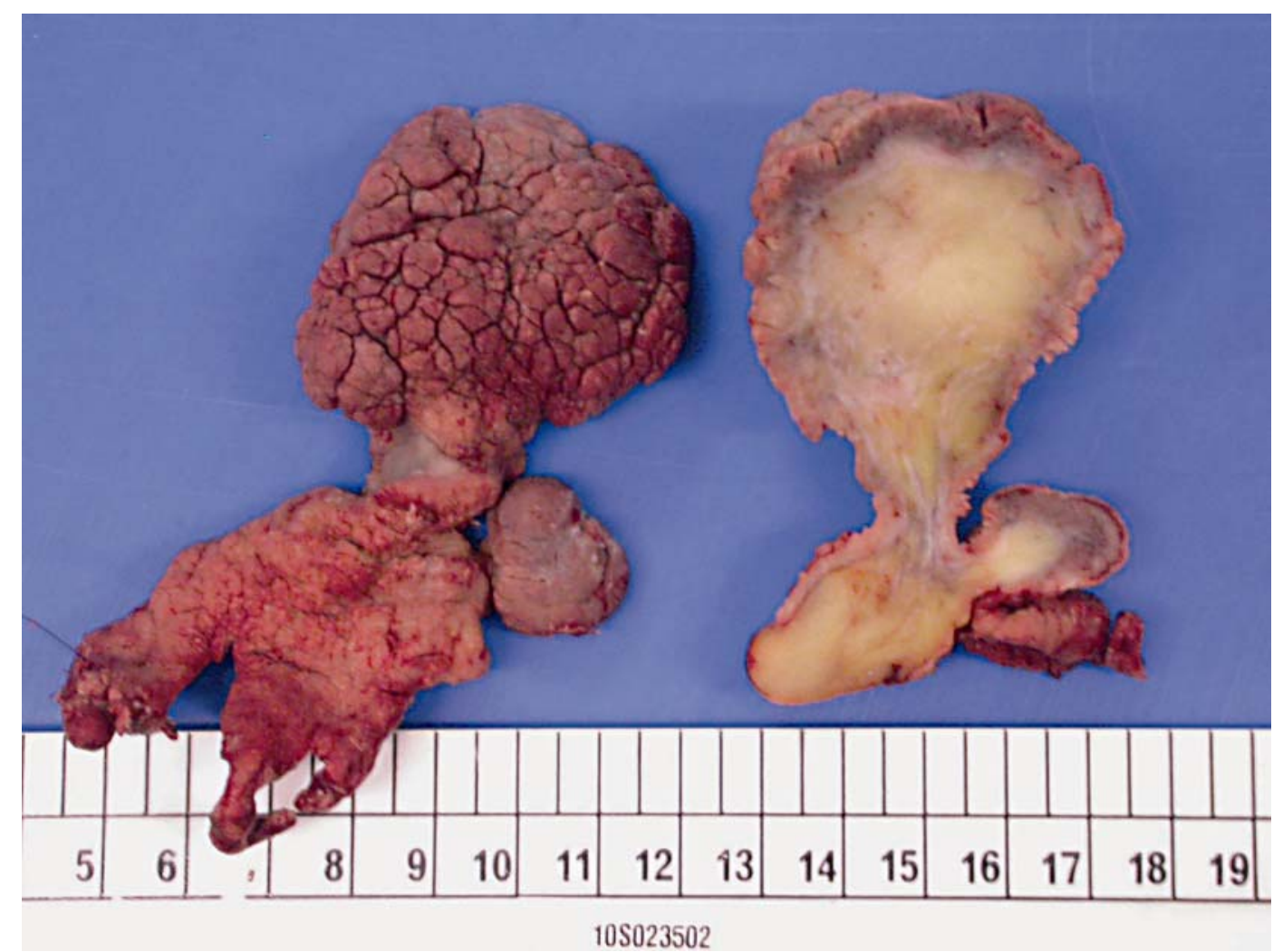

Fig. 3. Macroscopic appearance of the resected specimen, demonstrating a broad base of nearly $4 \mathrm{~cm}$ (confirming the need of surgery rather than endoscopic excision for complete removal) with wasting around the site of intussusception. The mucosa demonstrates signs of chronic injury in terms of ulceration and hyperproliferative surface. The transected surface shows typical features of a submucosal lipoma.

\section{References}

1 Huang WH, Peng CY, Yu CJ, Chou JW, Feng CL: Endoloop-assisted unroofing for the treatment of symptomatic duodenal lipomas. Gastrointest Endosc 2008;68:1234-1236.

2 Mayo CW, Pagtaluman RJG, Brown DJ: Lipoma of the alimentary tract. Surgery 1963;53:598-603.

-3 Blanchet MC, Arnal E, Paparel P, Grima F, Voiglio EJ, Caillot JL: Obstructive duodenal lipoma successfully treated by endoscopic polypectomy. Gastrointest Endosc 2003;58:938-939.

4 Tung CF, Chow WK, Peng YC, Chen GH, Yang DY, Kwan PC: Bleeding duodenal lipoma successfully treated with endoscopic polypectomy. Gastrointest Endosc 2001;54:116-117.

5 Michel LA, Ballet T, Collard JM, Bradpiece HA, Haot J: Severe bleeding from submucosal lipoma of the duodenum. J Clin Gastroenterol 1988;10:541-545.

6 Waligore MP, Strephens DH, Soule EH, McLeod RA: Lipomatous tumors of the abdominal cavity: CT appearance and pathologic correlation. AJR Am J Roentgenol 1981;137:539-545.

7 Nakamura S, Iida M, Suekane H, Matsui T, Yao T, Fujishima M: Endoscopic removal of gastric lipoma: diagnostic value of endoscopic ultrasonography. Am J Gastroenterol 1991;86:619-621.

-8 Yu HG, Ding YM, Tan S, Luo HS, Yu JP: A safe and efficient strategy for endoscopic resection of large, gastrointestinal lipoma. Surg Endosc 2007;21:265-269.

$\triangleright_{9}$ Chang CW, Chu CH, Shih SC, Chen MJ, Yang TL, Chang WH: Duodenal polypoid lipoma with bleeding. Am J Surg 2010;200:49-50. 


\begin{tabular}{r|l|l|l} 
Case Reports in & $\begin{array}{l}\text { Case Rep Gastroenterol 2011;5:183-188 } \\
\text { DOl: 10.1159/000327219 }\end{array}$ & $\begin{array}{l}\text { Published online: } \\
\text { April 13, 2011 }\end{array}$ & $\begin{array}{l}\odot \text { 2011 S. Karger AG, Basel } \\
\text { ISSN 1662-0631 } \\
\text { www.karger.com/crg }\end{array}$ \\
\hline
\end{tabular}

10 Mohamed HK, Suresh CC, Alexander KG, Neena M: Bleeding duodenal lipoma treated with endoscopic polypectomy. Trop Gastroenterol 2008;29:167-168.

11 Murata A, Osoegawa T, Ijyu M, Kanayama K, Tanaka M, Nakamura K: Pedunculated duodenal lipoma treated with endoscopic polypectomy with a detachable snare. Fukuoka Igaku Zasshi 2008;99:131-135.

12 Long BW, Goodwin E, Halford P, Almas J: Diagnosis and endoscopic resection of a bleeding duodenal lipoma. J Miss State Med Assoc 2008;49:3-6.

13 Sou S, Nomura H, Takaki Y, Nagahama T, Matsubara F, Matsui T, Yao T: Hemorrhagic duodenal lipoma managed by endoscopic resection. J Gastroenterol Hepatol 2006;21:479-481. 